\title{
DA SEBAGAI ADVERBIA ATAUKAH KONJUNGTOR? (KAJIAN GRAMATIKALISASI)
}

\author{
Agus Ridwan \\ Universitas Negeri Surabaya \\ (agusridwan@unesa.ac.id)
}

\begin{abstract}
ABSTRAK
Satuan bahasa da bisa digunakan sebagai adverbia lokal. Selain sebagai adverbia, satuan bahasa da juga bisa digunakan sebagai konjungtor subordinatif kausal atau temporal. Berdasar pada penggunaan teori gramatikalisasi, adverbia $d a$ merupakan satuan bahasa yang memiliki struktur lama (schwache Grammatikalisierung). Adapun satuan bahasa $d a$ sebagai konjungtor subordinatif kausal atau temporal itu berstruktur baru (starke Grammatikalisierung).

Kata kunci: adverbia, konjungtor, gramatikalisasi
\end{abstract}

\section{A. PENDAHULUAN}

Gramatikalisasi merupakan salah satu teori linguistik yang digunakan untuk mendeskripsikan perubahan atau perkembangan suatu bahasa. Perubahan/perkembangan tersebut bisa terjadi pada tiap tataran linguistik, umpamanya bentuk satuan bahasa dan/atau beserta maknanya. ${ }^{1}$ Sampai saat ini, khususnya di Jerman objek kajian gramatikalisasi cukup intensif dikaji.

Salah satu objek kajian gramatikalisasi yang akan dikaji dalam artikel ini adalah satuan bahasa $d a$. Artikel ini mencoba untuk mendeskripsikan perkembangan atau perubahan satuan bahasa $d a$. Satuan bahasa $d a$ bisa digunakan baik sebagai adverbia maupun sebagai konjungtor. Sebagai adverbia, satuan bahasa $d a$ merupakan salah satu kelas kata yang tidak berinfleksi dan digunakan sebagai

1 Lihat teori gramatikalisasi pada subbab berikutnya. 
petanda lokal (Nübling 2009:569-572). Sebagai petanda lokal seperti pada kalimat $(1)^{2}$ satuan bahasa tersebut mempunyai fungsi sebagai Angabe/Adjunkte ${ }^{3}$.

(1) Ich komme gerade von dort.

Pron VFn Adv Prep Adv

'Baru saja saya datang dari sana'

(Klosa dkk. 2001:392)

Selanjutnya, Nübling (2009:569-572) juga berpandangan bahwa sebagai kelas kata yang tidak berinfleksi, adverbia $d a$ juga memiliki fungsi lain, yakni sebagai Ergänzungen ${ }^{4}$ seperti:

(2) Ich bin bis Sonntag da.

Pron VFn Prep Nom Adv

'Saya (berada) di sana/di sini sampai pada hari minggu'

(Klosa dkk. 2001:392)

(3) Ich wohne da.

Pron VFn Adv

'Saya tinggal di sana/di sini'

(Klosa dkk. 2001:345)

(4) Da ist die Haltestelle.

Adv VFn Art Nom

'Pompa bensinnya (berada) di sana'

(Klosa dkk. 2001:345)

Penggunaan lain dari satuan bahasa $d a$ adalah konjungtor subordinatif. Sebagai konjungtor subordinatif, $d a$ menghubungkan antara induk kalimat dengan anak kalimat. Konjungtor tersebut memiliki petanda kausal, misalnya $d a$ pada kalimat (5), (6) (Klosa dkk. 2001:346; Wolski, 2011:324).

(5) Da er krank war, konnte er nicht kommen.

Konj Pron Adj VFn VFn Pron Neg VIfn

2 Selain sebagai petanda lokal, satuan bahasa da juga bisa digunakan sebagai petanda-petanda lainnya, misalnya petanda temporal (zu dieser Zeit), petanda Konjunktional adverbien (deshalb). Namun, variasi penggunaan tersebut merupakan bentuk informel dalam bahasa sehari-hari (Wolski 2011:324).

3 Angabe/Adjunkte merupakan suatu frase yang berfungsi untuk memodifikasi salah satu unsur kalimat.

4 Ergänzung adalah satuan bahasa berupa frase yang tergantung pada satuan bahasa lainnya, misalnya verba, preposisi. 
'Karena (dia) sakit, dia tidak bisa datang'

(Klosa dkk. 2001:346)

(6) Da ich ihn gut kenne, habe ich zuerst ihn gefragt.

Konj Pron Pron Adj VFn VFn Pron Adv Pron VInf

'Pertama-tama saya bertanya kepadanya, karena saya mengenalnya dengan

baik'

(Wolski, 2011:324)

Klosa dkk. juga mengemukakan pendapat bahwa selain sebagai konjungtor subordninatif kausal, satuan bahasa da juga bisa digunakan sebagai konjungtor subordinatif yang memiliki petanda temporal seperti pada kalimat (7) (2001:347).

(7) Da er noch reich war, hatte er viele Freunde.

Konj Pron Adv Adj VFn VFn Pron Pron Nom

'Ketika (dia) masih kaya, dia memiliki banyak teman'

(Klosa dkk. 2001:346)

Seperti pendapat Klosa dkk. (2001), Wolski juga berpandangan bahwa satuan bahasa $d a$ tidak hanya bisa digunakan sebagai konjungtor subordinatif kausal, melainkan juga bisa digunakan sebagai konjungtor subordinatif temporal seperti pada kalimat (8) (2011:324). ${ }^{5}$

(8) Jetzt, da die Buchmessen zu Ende ist, gibt es wieder freie Adv Konj Art Nom Prep Nom VFn VFn Pron Adv Adj

\section{Hotelzimmer.}

Nom

'Setelah pekan raya buku berakhir, ada banyak kamar hotel yang kosong pada saat ini'

(Wolski, 2011:324)

Gambaran mengenai perbedaan dan persamaan penggunaan dari satuan bahasa $d a$ sebagai adverbia dan konjungtor tersebut cukup jelas. Namun deskripsi tersebut masih meninggalkan permasalahan yang cukup menarik untuk dikaji, yakni

5 Namun yang membedakan di antara dua pendapat tersebut adalah konjungtor subordinatif temporal $d a$ seperti yang diajukan Klosaa dkk. (2001:346) itu mempunyai padanan dengan konjungtor subordinatif als, nun atau wenn yang penggunaannya memiliki waktu kejadian yang bersamaan, sedangkan konjungtor subordinatif temporal $d a$ seperti yang diajukan Wolski (2011:324) mempunyai padanan dengan konjungtor subordinatif nachdem yang penggunaannya memiliki waktu kejadian yang berbeda. 
apakah adverbia $d a$ dan konjungtor subordinatif $d a$ yang mempunyai bentuk yang sama itu memang terbentuk secara kebetulan atau salah satu di antara keduanya itu yang mendasari terbentuknya satuan bahasa lainnya, misalnya adverbia $d a$ merupakan dasar dari pembentuk konjungtor subordinatif $d a$ atau sebaliknya. Permasalahan seperti ini sering dikesampingkan. Oleh karena itu, kajian ini mencoba untuk mendeskripsikan proses pembentukan satuan bahasa da baik sebagai adverbia atau konjungtor.

\section{A. Teori Gramatikalisasi}

Teori gramatikalisasi merupakan salah satu teori yang digunakan untuk mendeskripsikan perkembangan atau perubahan bahasa, yakni proses terbentuknya satuan bahasa yang berstruktur baru atau bermakna baru/bermakna gramatikal (starke Grammatikalisierung). Tataran linguistik dalam teori gramatikalisasi meliputi bidang fonetik, (morfo)sintaksis, dan semantik baik secara paradigmatis maupun sintagmatis. Pada setiap tataran linguistik secara paradigmatis dan sintagmatis tersebut juga terdapat parameter yang digunakan untuk mendeskripsikan perkembangan atau perubahan satuan bahasa. Parameter yang digunakan pada bidang fonetik/fonemik secara paradigmatis adalah reduksi bunyi (phonetische Reduktion), parameter pada bidang (morfo)sintaksis terdiri dari paradigmatisasi (Paradigmatizierung), obligatorifisasi (Obligatorifizierung), dan parameter pada bidang semantik adalah reduksi makna (semantische Reduktion). Adapun secara sintagmatis terdapat fusi (Fusion) pada bidang fonetik, koalesens (Koaleszenz) dan topologisasi (Topologisierung) pada bidang (morfo)sintaksis serta synsemantisasi (Synsemantisierung) pada bidang semantik. ${ }^{6}$ Berikut ini jenisjenis parameter tersebut dalam tabel.

Tabel 1

Parameter Proses Gramatikalisasi

\begin{tabular}{|c|c|c|}
\hline & Paradigmatis & Sintagmatis \\
\hline Fonetik & reduksi bunyi & fusi \\
\hline (Morfo)sintaksis & paradigmatisasi & koalesens \\
\hline
\end{tabular}

6 Bandingkan teori gramatikalisasi dari Lehmann (1995) dan Henn-Memmesheimer (2004, 2006). 


\begin{tabular}{|c|c|c|}
\hline & obligatorifisasi & topologisasi \\
\hline Semantik & reduksi makna & synsemantisasi \\
\hline
\end{tabular}

\section{B. PEMBAHASAN}

Kajian ini merupakan bidang gramatikalisasi yang berobjekan satuan bahasa $d a$ dan berfokus pada dua bidang, yaitu bidang (morfo)sintaksis dan bidang (semantik) secara paradigmatis dan sintagmatis. Adapun bidang fonetis dalam kajian ini tidak dikupas dengan berbagai pertimbangan. Untuk lebih jelasnya mengenai tiga bidang tersebut akan dipaparkan berikut.

1. Bidang Fonetik

Pada bidang fonetik baik secara paradigmatis maupun sintagmatis, antara adverbia $d a$ dan konjungsi subordinatif kausal dan temporal $d a$ tidak mengalami perubahan bunyi, yakni reduksi bunyi ataupun fusi. Oleh karena itu, kesamaan bunyi yang dimiliki oleh satuan bahasa dengan kelas kata yang berbeda itu menyebabkan penggunaan proses gramatikalisasi pada bidang fonetik tidak memungkinkan untuk melihat perkembangan atau perubahan satuan bahasa tersebut.

\section{Bidang (Morfo)Sintaksis}

Karena keterbatasan penggunaan parameter pada bidang fonetik yakni reduksi bunyi dan fusi, kajian ini mencoba untuk menggunakan parameter paradimatisasi (Paradigmatizierung) dan obligatorifisasi (Obligatorifizierug) secara paradigmatis. Adapun parameter yang digunakan secara sintagmatis adalah koalesens (Koaleszenz) dan topologisasi (Topologisierung).

Pada bidang (morfo)sintaksis secara paradigmatis, satuan bahasa $d a$ sebagai adverbia memiliki hubungan yang relatif tidak terbatas dengan satuan bahasa lainnya, misalnya adverbia $d a$ pada kalimat (9) dengan adverbia dort pada kalimat (9a), adverb hier pada kalimat (9b), frase preposisi in Mannheim pada kalimat (9c), frase preposisi im dritten Stock pada kalimat (9d), atau satuan bahasa yang memiliki fungsi sebagai lokale Ergänzung.
(9)
Ich
wohne
da. 
Pron VFn Adv

'Saya tinggal di sana'

(Klosa dkk. 2001:345)

(9a) Ich wohne dort

Pron VFn Adv

'Saya tinggal di sana'

(9b) Ich wohne hier

Pron VFn Adv

'Saya tinggal di sini'

(9c) Ich wohne

in Mannheim.

Pron VFn Prep Nom

'Saya tinggal di Mannheim'

(9d) Ich wohne im dritten Stock.

Pron VFn Prep+Art Num Nom

'Saya tinggal di lantai tiga'

$(9 \mathrm{e})$

Berdasar pada teori gramatikalisasi pada bidang (morfo)sintaksis secara paradigmatis, adverbia da yang memiliki hubungan yang tidak terbatas dengan satuan bahasa lainnya seperti adverbia lokal atau frase preposisi sebagai petanda lokal merupakan satuan bahasa yang memiliki struktur lama (schwache Gramatikalisierung).

Selain itu, adverbia $d a$ sebagai satuan bahasa yang berstruktur lama itu (schwache Gramatikalisierung) bisa disubstitusikan dengan satuan bahasa lainnya seperti adverbia dort, adverbia hier, frase preposisi in Mannheim, frase preposisi im dritten Stock, atau satuan bahasa yang memiliki fungsi sebagai lokale Ergänzungseperti pada kalimat (10).

$\begin{array}{ll}\text { (10) Ich } & \text { wohne da. } \\ \text { Pron } & \text { VFn Adv } \\ & \text { dort 'di sana' } \\ & \text { hier 'di sini' }\end{array}$




\section{in Mannheim 'di Mannheim' \\ im dritten Stock 'di lantai tiga'}

'Saya tinggal di sana'

Selanjutnya, satuan bahasa $d a$ yang memiliki struktur lama (schwache Grammatikalisierung) dengan penggunaaan salah satu parameter dalam teori gramatikalisasi pada bidang (morfo)sintaksis secara paradigmatis, yakni proses paradigmatisasi (Paradigmatizierung) bisa menjadi satuan bahasa yang berstruktur baru (starke Grammatikalisierung). Satuan bahasa dengan struktur baru tersebut memiliki hubungan yang terbatas dengan satuan bahasa lainnya, yakni satuan bahasa $d a$ sebagai konjungtor subordinatif kausal pada kalimat (11) memiliki keterbatasan hubungan dengan konjungtor subordinatif kausal lainnya, seperti subjungtor weil pada kalimat (11a) atau subjungtor zumal pada kalimat (11b).

$\begin{array}{lllll}\text { Da } & \text { er } & \text { krank } & \text { war, konnte er nicht kommen. } \\ \text { Konj } & \text { Pron Adj VFn } & \text { VFn Pron Neg VIfn }\end{array}$

'Karena (dia) sakit, dia tidak bisa datang'

(Klosa dkk. 2001:346)

$\begin{array}{rlllll}\text { (11a) Weil } & \text { er krank } & \text { war, konnte er nicht kommen. } \\ \text { Konj } & \text { Pron Adj VFn } & \text { VFn Pron Neg VIfn } & \end{array}$

'Karena (dia) sakit, dia tidak bisa datang'

(11b)Zumal er krank war, konnte er nicht kommen.

Konj Pron Adj VFn VFn Pron Neg VIfn

'Karena (dia) sakit, dia tidak bisa datang'

Seperti konjungtor subordinatif kausal $d a$, satuan bahasa $d a$ sebagai konjungtor subordinatif temporal pada kalimat (12) juga memiliki keterbatasan hubungan dengan konjungtor subordinatif temporal lainnya seperti konjungtor subordinatif als pada kalimat (12a), konjungtor subordinatif nun pada kalimat (12b) atau konjungtor subordinatif wenn pada kalimat (12c). Subjungtor temporal $d a$ yang memiliki hubungan yang terbatas dengan subjungtor temporal lainnya itu merupakan satuan bahasa yang juga berstruktur baru. 
(12) Da er noch reichwar, hatte er viele Freunde.

Konj Pron Adv Adj VFn VFn Pron Pron Nom

'Ketika dia masih kaya, dia memiliki banyak teman'

(Klosa dkk. 2001:346)

(12a) Als er noch reich war, hatte er viele Freunde.

Konj Pron Adv Adj VFn VFn Pron Pron Nom

'Ketika dia masih kaya, dia memiliki banyak teman'

(12b)Nun er noch reich war, hatte er viele Freunde.

Konj Pron Adv Adj VFn VFn Pron Pron Nom

'Ketika dia masih kaya, dia memiliki banyak teman'

12c) Wenn er noch reich war, hatte er viele Freunde.

Konj Pron Adv Adj VFn VFn Pron Pron Nom

'Ketika dia masih kaya, dia memiliki banyak teman'

Konjungtor subordinatif kausal $d a$ sebagai satuan bahasa yang berstruktur baru (starke Grammatikalisierung) tersebut tidak hanya mempunyai hubungan yang terbatas dengan konjungtor subordinatif kausal lainnya, melainkan juga mempunyai keterbatasan kookurensi, yakni konjungtor subordinatif kausal $d a$ pada kalimat (13) itu hanya bisa disubstitusikan dengan jenis konjungtor subordinatif yang sama seperti konjungtor weil, zumal. $^{7}$

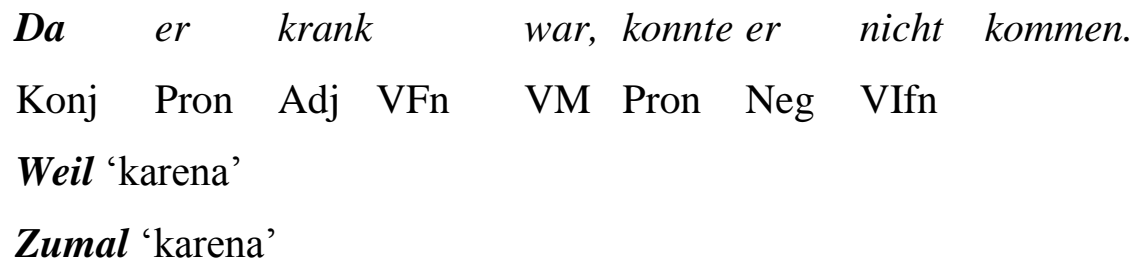

'Karena (dia) sakit, dia tidak bisa datang'

Demikian pula satuan bahasa $d a$ sebagai konjungtor subordinatif temporal memiliki kookurensi yang terbatas dengan konjungtor subordinatif lainnya. Oleh karena itu, konjungtor subordinatif temporal $d a$ pada kalimat (14) hanya bisa disubtitusikan dengan subjungtor als, nun, wenn.

\begin{tabular}{|c|c|c|c|c|}
\hline (14) $\boldsymbol{D a}$ & noch & reich war, & hatte er & Freunde. \\
\hline Konj & Pron Adv & Adj VFn & VFn Pron Pron & Nom \\
\hline
\end{tabular}

Bandingkan dengan satuan bahasa denn 'karena' yang memiliki petanda kausal juga. 


\section{Nun 'ketika'}

\section{Wenn 'ketika'}

'Ketika dia masih kaya, dia memiliki banyak teman'

Pada bidang (morfo)sintaksis secara sintagmatis, satuan bahasa $d a$ sebagai adverbia yang memiliki fungsi sebagai Angabepada kalimat (15) tidak mempunyai ketergantungan pada verba kommen 'datang'. Oleh karena itu, adverbia $d a$ pada kalimat (15) terutama berkaitan dengan penggunaannya sebagai Angabe itu merupakan satuan bahasa yang memiliki struktur lama (schwache Grammatikalisierung).

(15) $I c h$ komme gerade von dort.

Pron VFn Adv Prep Adv

'Baru saja saya datang dari sana'

(Klosa dkk. 2001:392)

Jika dibandingkan dengan fungsinya sebagai Ergänzung, adverbia $d a$ secara formal tergantung pada verba sein 'berada'pada kalimat (16), (17) dan verba wohnen 'tinggal' pada kalimat (18).

(16)

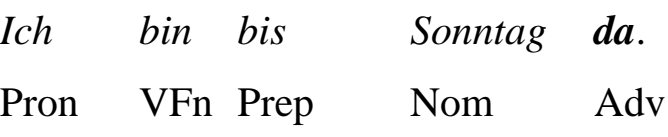

'Saya (berada) di sana sampai pada hari minggu'

(Klosa dkk. 2001:392)

(17)

$\begin{array}{lll}\text { Da } & \text { ist die } & \text { Haltestelle. } \\ \text { Adv } & \text { VFn } & \text { ArtNom }\end{array}$

'Pompa bensinnya berada di sana'

(Klosa dkk. 2001:345)

(18) Ich wohne da.

Pron VFn Adv

'Saya tinggal di sana'

(Klosa dkk. 2001:345)

Melalui proses Koaleszens, adverbia $d a$ secara formal bisa bergantung pada satuan bahasa lainnya, yakni pada verba, terutama berkaitan dengan penggunaannya sebagai Ergänzung seperti pada kalimat (16), (17), (18) 
sebelumnya. ${ }^{8}$ Adverbia $d a$ dalam konstruksi tersebut merupakan satuan bahasa yang mempunyai struktur lama. Selain itu, melalui proses yang sama, yakni Koaleszens, satuan bahasa da sebagai kongjungsi subordinatif kausal sangat tergantung pada satuan bahasa lainnya (induk kalimat) seperti er konnte nicht kommen 'dia tidak bisa datang' pada kalimat (19).

$\begin{array}{llllll}\text { Da } & \text { er } & \text { krank } & \text { war, konnte er nicht kommen. } \\ \text { Konj Pron Adj VFn } & \text { VFn Pron Neg VIfn } & \end{array}$

'Karena (dia) sakit, dia tidak bisa datang'

(Klosa dkk. 2001:346)

Seperti konjungsi subordinatif kausal, melalui proses Koaleszens, satuan bahasa $d a$ sebagai konjungsi subordinatif temporal juga mempunyai ketergantungan pada induk kalimat seperti er hatte viele Freunde 'dia mempunyai banyak teman' pada kalimat (20). Satuan bahasa yang memiliki ketergantungan dengan satuan bahasa lainnya tersebut berstruktur lama.

$\begin{array}{lllll}\text { Da } & \text { er noch reich war, hatte er viele } & \text { Freunde. } \\ \text { Konj Pron Adv Adj VFn VFn Pron Pron } & \text { Nom }\end{array}$

'Ketika dia masih kaya, dia memiliki banyak teman'

(Klosa dkk. 2001:346)

Pada bidang (morfo)sintaksis secara sintagmatis, satuan bahasa $d a$ sebagai adverbia lokal juga memiliki pola urutan yang relatif bebas, yakni adverbia $d a$ bisa menempati posisi Vorfeld, yakni sebelum verba finit (VFn) ${ }^{9}$ wohnen 'tinggal' pada kalimat (21) atau mengisi slot Mittelfeld, yakni sesudah linke Satzklammer yang diisi oleh verba finit wohnen 'tinggal' pada kalimat (22) atau di antara linke Satzklammer yang diisii oleh verba finit berupa verba modal müssen 'harus/mesti' dan rechte Satzklammer yang diisi oleh verb infinit (Vinf) wohnen 'tinggal' pada kalimat (23) atau berkedudukan di Nachfeld yaitu setelah verba infinit arbeiten '(be)kerja' pada kalimat (24).

$\begin{array}{lll}\text { Da } & \text { wohne } & \text { ich. } \\ \text { Adv } & \text { VFn } & \text { Pron }\end{array}$

8 Adverbia da yang mempunyai fungsi sebagai Angabe merupakan satuan bahasa yang berstruktur lama, sedangkan struktur dari adverbia da yang berfungsi sebagai Ergänzung masih baru.

9 Verba finit merupakan verba yang mengalami infleksi atau konjugasi sesuai dengan subjek kalimat. 
'Saya tinggal di sana/di sini'

(22)
Ich wohne
da.
Pron VFn
Adv

'Saya tinggal di sana/di sini'

(23)
Ich muss da wohnen.
Pron VFn Adv VInf

'Saya tinggal di sana/di sini'

$\begin{array}{llll}\text { Er } & \text { möchte } & \text { arbeiten da, wo } & \text { er will. } \\ \text { Pron } & \text { VFn } & \text { VInf Adv Pron Pron } & \text { VFn }\end{array}$

'Dia/Ia ingin bekerja di sana/di sini sesuai dengan keinginannya'

Pada bidang yang sama, melalui proses Topologisierung, satuan bahasa $d a$ baik sebagai konjungsi subordinatif kausal maupun sebagai konjungsi subordinatif temporal itu juga berstruktur lama karena mempunyai keterbatasan pola urutan katanya. Konjungsi subordinatif kausal dan temporal da hanya bisa menempati posisi Vorvorfeld pada kalimat (25), (26) atau posisi Nachfeld pada kalimat (27), (28).

Da er krank $\quad$ war, konnte er nicht kommen.
Konj Pron Adj VFn VFn Pron Neg VIfn
'Karena (dia) sakit, dia tidak bisa datang'

Da er noch reich war, hatte er viele Freunde.

Konj Pron Adv Adj VFn VFn Pron Pron Nom

'Ketika (dia) masih kaya, dia memiliki banyak teman'

$\begin{array}{lllll}\text { Er } & \text { konnte } & \text { nicht kommen, da er } & \text { krank war. } \\ \text { Pron } & \text { VFn Neg } & \text { VIfn Konj Pron Adj VFn } & \end{array}$

'Dia tidak bisa datang, karena (dia) sakit'

(28) Er hatte viele Freunde, da er krank war.

Pron VFn Pron Nom Konj Pron Adj VFn

'Dia memiliki banyak teman, ketika (dia) masih kaya'

\section{Bidang Semantik}

Pada bidang semantik secara paradigmatis, satuan bahasa $d a$ memiliki gramatikalisasi lemah, yakni satuan bahasa tersebut memiliki seperangkat ciri- 
ciri semantis tertentu, misalnya adverbia $d a$ dengan ciri-ciri semantik berikut merupakan satuan bahasa yang memiliki schwache Grammatikalisierung.

Adverbia $\quad[[\mathrm{da}]]=[+$ lokal $]$

$$
\begin{aligned}
& \text { [+/- dort] 'di sana' } \\
& \text { [+/- hier] 'di sini' } \\
& \text { [+/- zu Hause] 'di rumah' } \\
& \text { [+/- in Mannheim] 'di Mannheim' } \\
& \text { [+/- in Berlin] 'di berlin' }
\end{aligned}
$$

Secara paradigmatis, pada bidang yang sama, satuan bahasa $d a$ sebagai konjungsi subordinatif kausal dan temporal merupakan satuan bahasa yang mempunyai starke Grammatikalisierung, yakni melalui proses reduksi makna, satuan bahasa tersebut kehilangan ciri-ciri semantiknya.

Konjungsi subordinatif kausal $[[\mathrm{da}]]=[+$ Kedudukan verba di akhir anak kalimat]

$$
\begin{aligned}
& \text { [- lokal] 'petanda tempat' } \\
& \text { [- dort] 'di sana' } \\
& \text { [- hier] 'di sini' } \\
& \text { [- zu Hause] 'di rumah' } \\
& \text { [- in Mannheim] 'di Mannheim' } \\
& \text { [- in Berlin] 'di berlin' }
\end{aligned}
$$

Konjungsi subordinatif temporal $[[\mathrm{da}]]=[+$ Kedudukan verba di akhir anak kalimat]

$$
\begin{aligned}
& \text { [- lokal] 'petanda tempat' } \\
& \text { [- dort] 'di sana' } \\
& \text { [- hier] 'di sini' } \\
& \text { [- zu Hause] 'di rumah' } \\
& \text { [- in Mannheim] 'di Mannheim' } \\
& \text { [- in Berlin] 'di berlin' }
\end{aligned}
$$

Secara sintagmatis, pada bidang semantik, adverbia $d a$ juga memiliki schwache Grammatikalisierunng. Satuan bahasa tersebut memiliki 
autosemantika atau makna leksikal (lexikalische Bedeutung). Makna leksikal dari adverbia $d a$ berupa petanda lokal, yakni dort 'di sana' atau hier 'di sini' seperti pada kalimat (29).

$\begin{array}{lll}\text { (29) } & \text { wohne } & \text { da. } \\ \text { Pron } & \text { VFn }\end{array}$

'Saya tinggal di sana/di sini'

Melalui proses synsemantisasi, autosemantika dari satuan bahasa $d a$ sebagai adverbia itu mengalami pelesapan makna leksikalnya yakni petanda lokal. Satuan bahasa tersebut memiliki makna gramatikal (grammatikalische Bedeutung) atau starke Grammatikalisierung, misalnya satuan bahasa da sebagai konjungsi subordinatif kausal pada kalimat (30) dan konjungsi subordinatif temporal pada kalimat (31).

Da ich ihn gut kenne, habe ich zuerst ihn gefragt.

Konj Pron Pron Adj VFn VFn Pron Adv Pron VInf

'Karena saya kenal baik dengan dia, saya yang pertama bertanya kepadanya'

(Wolski 2011:324)

(33) Da er noch reich war, hatte er viele Freunde.

Konj Pron Adv Adj VFn VFn Pron Pron Nom

'Ketika (dia) masih kaya, dia memiliki banyak teman'

\section{PENUTUP}

Berdasar pada penggunaan teori gramatikalisasi, baik pada bidang (morfo)sintaksis maupun pada bidang semantik secara paradigmatis dan sintagmatis, satuan bahasa $d a$ sebagai adverbia merupakan satuan bahasa yang memiliki struktur baru/schwache Grammatikalisierung yakni satuan bahasa tersebut (a) mempunyai hubungan yang tak terbatas dengan satuan bahasa lainnya khususnya adverbia lokal, (b) bisa disubstitusikan dengan adverbia lokal lainnya yang tak terbatas, dan (c) memiliki autosemantika. Sebaliknya satuan bahasa da sebagai subjungsi kausal dan temporal (a) memiliki keterbatasan hubungan 
dengan subjungsi lainnya; (b) substitusi yang dimilikinya sangat terbatas, yakni tidak semua subjungsi kausal dan temporal bisa menggantikan subjungsi $d a$; dan (c) makna dari satuan bahasa tersebut tidak lagi berupa makna leksikal, melainkan makna gramatikal.

\section{DAFTAR PUSTAKA}

Engel, Ulrich. (2009): Deutsche Grammatik. 2., durchgesehene Auflage. München: IUDICIUM Verlag.

Henn-Memmesheimer, Beate/Bärnert-Fürst, Ute/Denzer, Anke/Gallery, Heike (1998): Nonstandard als Faktor bei der Strukturierung kommunikativer Siatuationen. Zur charakteristischen Verteilung von Indikatoren und Markern. In: Sprachliche Varianz als Ergebnis von Handlungswahl (= Reihe Germanistische Linguistik Bd. 198). Henn-Memmesheimer, Beate, Hrsg. Tübingen: Max Niemeyer Verlag, S. 157-178.

Henn-Memmesheimer, Beate. (2004): Syntaktische Minimalformen: Grammatikalisierungen in einer medialen Nische. In: Franz Patocka / Peter Wiesinger (Hrg.): Morphologie und Syntax deutscher Dialekte und Historische Dialektologie des Deutschen. Beiträge zum 1. Kongress der Internationalen Gesellschaft für Dialektologie des Deutschen, Marburg/Lahn, 5.-8. März 2003. Wien: Edition Präsens.

Henn-Memmesheimer, Beate (2006): Grammatikalisierungen in verschiedenen Diskurstraditionen. In: Grammatische Untersuchungen. Analysen und Reflexionen. Gisela Zifonun zum 60 Geburtstag (= Studien zur deutschen Sprache Bd. 36). Breindl, Eva/Gunkel, Lutz/Strecker, Bruno, Hrsg. Tübingen: Narr 2006. S. 533-551.

Hentschel, Elke/Weydt, Harald (2003): Handbuch der deutschen Sprache. 3., völlig neu bearbeitete Auflage. Berlin/New York: Walter de Gruyter.

Hentschel, Elke/Vogel, Peter M. (2009): Deutsche Morphologie. Berlin/New York: Walter de Gruyter.

Klosa, Annette dkk. (2001): Deutsches Universalwörterbuch: 4., neu bearbeitete und erweiterte Auflage. Mannheim/Leipzig/Wien/Zürich: Dudenverlag.

Lehmann, Cristhian (1995): Synsemantika. In: Syntax Teilband 2 (=Handbücher zur Sprach- und Kommunikationswissenschaft Bd. 9.2) Ungeheuer, Gerold/ Steger, Hugo/Wiegand, Herbert Ernst, Hrsg. Berlin/New York: Walter de Gruyter.

Nübling, Damaris (2009): Die nicht flektierbaren Wortarten. In: Die Grammatik: Un-entbehrlich für richtiges Deutsch (= Duden Bd. 4). 8., überarbeitete Auflage. Wermke, Matthias/Kunkel-Razum, Kathrin/Scholze-Stubenrecht, Werner, Hrsg. Mannheim/Wien/Zürich: Dudenverlag.

Wolski, Peter. (2011): Deutsches Wörterbuch. Stuttgart: Ernst Klett Sprachen $\mathrm{GmbH}$.

Zifonun, Gisele/Hoffmann, Ludger/Strecker, Bruno (1997): Grammatik der deutschen Sprache, 3 Bde. In: Eroms, Hans-Werner/Stickel, Gerhard/Zifonun, Gisela (Hrsg.) Schriften des Insituts für deutsche Sprache 7, 1-3. Berlin/New York: Walter de Gruyter. 